\title{
Salidroside protects SH-SY5Y from pathogenic $\alpha$-synuclein by promoting cell autophagy via mediation of mTOR/p70S6K signaling
}

\author{
SHASHA CHEN ${ }^{1 *}$, FENG CAI $^{2 *}$, JIRONG WANG $^{1}$, ZHOUXIN YANG $^{1}$, \\ CHI GU ${ }^{2}$, GUOFU WANG ${ }^{1}$, GENXIANG MAO ${ }^{1}$ and JING YAN ${ }^{1}$ \\ ${ }^{1}$ Zhejiang Provincial Key Laboratory of Geriatrics, Department of Geriatrics, Zhejiang Hospital, Hangzhou, Zhejiang 310013; \\ ${ }^{2}$ Department of Neurosurgery, The Second Affiliated Hospital of Zhejiang University School of Medicine, \\ Hangzhou, Zhejiang 310009, P.R. China
}

Received September 4, 2018; Accepted April 11, 2019

DOI: $10.3892 / \mathrm{mmr} .2019 .10285$

\begin{abstract}
The abnormal aggregation of $\alpha$-synuclein ( $\alpha$-syn), which is an important pathological feature of Parkinson's disease (PD), is cytotoxic to dopaminergic neurons and causes cellular damage and apoptosis. Salidroside (SAL) is the main active component of the traditional Chinese medicine Rhodiola rosea. Previous research has demonstrated that SAL exerts cellular protection against cell senescence and neurodegeneration. However, the role and mechanism of action of SAL in PD remain unclear. The present study used overexpression of the wild-type and the A53T mutation of $\alpha$-syn to induce a neuronal model of PD in SH-SY5Y cells, which led to neuronal toxicity and a reduced cell proliferation index. SAL increased the cell proliferation index of both PD model groups in a dose-dependent manner. Additionally, SAL alleviated pathogenic phosphorylated (Ser129) $\alpha$-syn expression as well as the ratio of microtubule-associated proteins $1 \mathrm{~A} / 1 \mathrm{~B}$ light chain 3 (LC3)-I to LC3-II expression, which is related to autophagic function. Furthermore, the results suggested that the underlying mechanism for the SAL-induced protection of PD model neurons may involve the preservation of autophagy, which attenuates the phosphorylation of $\alpha$-syn in neurons predominantly via $\mathrm{mTOR} / \mathrm{p} 70 \mathrm{~S} 6 \mathrm{~K}$, and is independent of the PI3K/Akt signaling pathway.
\end{abstract}

Correspondence to: Professor Genxiang Mao or Professor Jing Yan, Zhejiang Provincial Key Laboratory of Geriatrics, Department of Geriatrics, Zhejiang Hospital, 12 Lingyin Road, Xihu, Hangzhou, Zhejiang 310013, P.R. China

E-mail: maodashi_176yeah@126.com

E-mail: zjicu@vip.163.com

${ }^{*}$ Contributed equally

Abbreviations: PD, Parkinson's disease; $\alpha$-syn, $\alpha$-synuclein; SAL, salidroside

Key words: SAL, $\alpha$-syn, PD, autophagy, mTOR

\section{Introduction}

Parkinson's disease (PD) is one of the most common neurodegenerative and motor disorders and principally affects people over the age of 50, with an increased prevalence with increasing age. The pathogenesis of PD has been proposed to be related to mitochondrial disturbance, oxidative stress, the inflammatory response of microglial cells or cell senescence (1). PD is characterized pathologically by the loss and/or dysfunction of dopaminergic (DA) neurons in the substantia nigra and histologically by the presence of Lewy body (LB) and Lewy neurite (LN) formation, comprised primarily of abnormal aggregates of $\alpha$-synuclein ( $\alpha$-syn) (2).

The $S N C A$ gene encodes $\alpha$-syn, a small (140 amino acid) protein that is mainly expressed in the brain, with a primarily pre-synaptic localization (3). Physiologically, $\alpha$-syn is an indispensable anti-apoptosis factor in DA neurons in the nigrostriatal pathway; however, pathologically, oligomeric and/or fibrillary forms of $\alpha$-syn lose their anti-apoptotic function and are cytotoxic to DA neurons. These pathological forms can be caused by certain mutations, such as a duplication or triplication of SNCA, or by abnormal metabolism of $\alpha$-syn (4-6). Moreover, it appears that pathological $\alpha$-syn aggregates can be transferred via cell-to-cell transfer, which seeds further $\alpha$-syn aggregation in other neurons in a 'prion-like' manner (7-10).

The autophagy pathway is one of the degradation systems for cytosolic proteins in the central nervous system. It has been confirmed that neuronal clearance of $\alpha$-syn aggregates relies on macroautophagy (a type of autophagy), because the aggregates cannot pass through the narrow proteasomal core for degradation (11). In addition, to halt PD development, autophagy may prevent the early events in $\alpha$-syn exosomal release and uptake by neurons (12). Conversely, $\alpha$-syn aggregates can impair autophagy in DA neurons by decreasing the clearance of autophagosomes, leading to neuronal death (13). Therefore, there seems to be a strong relationship between $\alpha$-syn aggregates and impaired autophagy in DA neurons during PD development, and the protection of neuronal autophagic function could be an effective therapeutic strategy against PD. 
Salidroside (SAL) is an ingredient extracted from the root of Rhodiola rosea, and is reported to have various pharmacological activities, including antioxidant, anti-apoptosis, anti-tumor, cardioprotective and hepatoprotective functions (14). A previous study showed that SAL could inhibit cell senescence by regulating p53, p21 and p16 expression in oxidant-impaired cells (15). Furthermore, SAL has been reported to play a role in the downregulation of reactive oxygen species (ROS) and amyloid- $\beta$ aggregation in damaged neurons $(16,17)$ and in the protection of myocardial cells via $\mathrm{PI} 3 \mathrm{~K} / \mathrm{Akt} / \mathrm{mTOR}$ signaling, which is related to autophagy repair (18)

The present study investigated the therapeutic potential of SAL in a PD cell model [overexpression of wild-type (WT) $\alpha$-syn or A53T mutation of $\alpha$-syn in SH-SY5Y cells] and explored the underlying mechanism of its autophagy promotion via the mTOR/p70S6K and PI3K/Akt signaling pathways.

\section{Materials and methods}

Materials. SAL (cat. no. S101157) and EDTA (cat. no. 431788) were purchased from Shanghai Aladdin Bio-Chem Technology Co., Ltd. Rapamycin (Rap; cat. no. HY-10219) and 3-methyladenine (3-MA; cat. no. HY-19312) were purchased from MedChemExpress. FBS (cat. no. 16000-044) and OPTI-MEM (cat. no. 51985-034) were purchased from Gibco (Thermo Fisher Scientific, Inc.). DMEM-F12 (cat. no. SH30023.01B) and MEM (cat. no. SH30024.01B) were purchased from HyClone (GE Healthcare Life Sciences). L-glutamine (cat. no. 1294808), sodium pyruvate (cat. no. 792500), non-essential amino acid (NEAA) solution (100X; cat. no. M7145) and MTT kit (cat. no. M5655) were purchased from Sigma-Aldrich (Merck KGaA). Penicillin-streptomycin (100X; cat. no. P1400-100), trypsin-EDTA $(0.25 \%$; cat. no. T1300-100) and agarose gel DNA extraction (cat. no. D1200) were purchased from Beijing Solarbio Science \& Technology Co., Ltd. DMSO (cat. no. 302A0316) was purchased from Ameresco, Inc. Tween-20 (cat. no. BYL40713) and Tris- $\mathrm{HCl}$ (pH 7.5) (cat. no. BYL40909) were purchased from JRDUN Biotechnology Co., Ltd. The Hoechst Staining kit (cat. no. C003), DAPI (cat. no. C1002) and $3 \%$ bovine serum albumin (BSA; cat. no. ST023) were purchased from Beyotime Institute of Biotechnology. LA $\mathrm{Taq}^{\circledR}$ (cat. no. RR02MA) and DNA marker (cat. no. 3590Q) were purchased from Takara Biotechnology Co., Ltd. T4 DNA Ligase (cat. no. 15224017), Anza ${ }^{\mathrm{TM}}$ 10-Pack restriction enzyme starter kit (for the digestion of HindIII-XhoI sites; cat. no. IVGN3006) and Lipofectamine ${ }^{\circledR} 2000$ (cat. no. 11668-019) were purchased from Invitrogen (Thermo Fisher Scientific, Inc.). High Pure dNTPs (cat. no. AD101) and competent DH5 $\alpha$ cells (cat. no. CD521) were purchased from Transgene SA. The plasmid extraction kit was purchased from Omega Bio-Tek, Inc. (cat. no. D6940), and pCDNA3.1(+) was purchased from Addgene, Inc. (cat. no. V790-20). The following antibodies were all purchased from Abcam with human species reactivity: pSer129- $\alpha$-syn (cat. no. ab51253), PI3K (cat. no. ab86714), phosphorylated (p)-PI3K (cat. no. ab151549), mTOR (cat. no. ab2732), p-mTOR (cat. no. ab109268), p70S6K (cat. no. ab32529), p-p70S6K (cat. no. ab5231) and microtubule-associated proteins 1A/1B light chain 3B (LC3B; cat. no. ab48394). The following antibodies were all purchased from CST with human species reactivity: Akt (cat. no. 4685), p-Akt (cat. no. 4060) and GAPDH (cat. no. 5174). The following secondary antibodies were purchased from Beyotime Institute of Biotechnology: Horseradish peroxidase (HRP)-conjugated goat anti-rabbit IgG (cat. no. A0208), HRP-conjugated donkey anti-goat IgG (cat. no. A0181), HRP-conjugated goat anti-mouse IgG (cat. no. A0216), Alexa Fluor 555-conjugated donkey anti-rabbit $\mathrm{IgG}(\mathrm{H}+\mathrm{L})$ (cat. no. A0453), Alexa Fluor 488-conjugated goat anti-rabbit $\operatorname{IgG}(\mathrm{H}+\mathrm{L})$ (cat. no. A0423) and Alexa Fluor 488-conjugated goat anti-mouse IgG $(\mathrm{H}+\mathrm{L})$ (cat. no. A0428).

Cell culture. SH-SY5Y cells (cat. no. BNCC100465; BeNa Culture Collection) were cultured in medium containing $10 \%$ FBS, $1 \%$ penicillin-streptomycin, $1 \%$ L-glutamine, $1 \%$ sodium pyruvate, $1 \%$ NEAA, $42.5 \%$ MEM and $42.5 \%$ DMEM-F12 under $5 \% \mathrm{CO}_{2}$ at $37^{\circ} \mathrm{C}$. Cells were seeded onto poly-L-lysine-coated plates and passaged when they reached 60-70\% confluence.

$\alpha-S y n$ plasmid transfection. Human WT/A53T- $\alpha$-syn overexpression plasmids were established by JRDUN Biotechnology. The PCR primers for the WT $\alpha$-syn in the vector plasmid pCDNA3.1(+) were as follows: Forward primer, 5'-CAAGCTGGCTAGCGTTTAAACTTAAGC TTGCCGCCACCATGGATGTATTCATG-3'; and reverse primer, 5'-GGGTTTAAACGGGCCCTCTAGACTCGA GTTAGGCTTCAGGTTCGTAGTC-3'. The PCR primers for the A53T $\alpha$-syn in the vector plasmid pCDNA3.1(+) were as follows: Forward primer, 5'-GGGAGTGGTGCA TGGTGTGACAACAGTGGCTGAGAAGACC-3'; and reverse primer, 5'-GGTCTTCTCAGCCACTGTTGTCAC ACCATGCACCACTCCC-3'. The two new plasmids were verified by digestion with the restriction enzymes HindIII and XhoI, according to the manufacturer's guidelines, and were sent to General Biosystems, Ltd. for sequencing. The sequencing results for full-length WT $\alpha$-syn were then aligned with a Homo sapiens SNCA mRNA sequence (accession no. NM_001146055.1) from NCBI (https://www. ncbi.nlm.nih.gov/), while the mutation A53T in $\alpha$-syn was determined by aligning the sequence with full-length WT $\alpha$-syn using Cluster Omega Alignment Tools (https://www.ebi.ac.uk/Tools/msa/clustalo/) (19). For the following experiments, cells $\left(5 \times 10^{5} /\right.$ well $)$ were transfected with WT/A53T- $\alpha$-syn plasmid $(1.6 \mu \mathrm{g})$ or the blank control pCDNA3.1(+) $(1.6 \mu \mathrm{g})$ for $6 \mathrm{~h}$, using Lipofectamine ${ }^{\circledR} 2000$, according to the manufacturer's instructions.

Measurement of cell viability. Cell viability was determined using the MTT assay, according to the manufacturer's instructions. First, SH-SY5Y cells were seeded into a 96-well plate at a concentration of $3 \times 10^{3} /$ well, with $100 \mu 1$ medium as the blank. After an overnight incubation, plates were first transfected with plasmids [mock (blank control), WT and A53T] for $6 \mathrm{~h}$ before the transfected solution was removed, and plates were then washed three times with PBS. Cells were then treated with one of a range of solutions (DMSO; 10 or $20 \mu \mathrm{M} \mathrm{SAL} ; 10 \mu \mathrm{M} \mathrm{SAL}+5 \mu \mathrm{M}$ Rap; $10 \mu \mathrm{M} \mathrm{SAL}+1 \mathrm{mM} 3-\mathrm{MA}$; or serum-free medium as the positive control) for various time periods $(0,24$ or $48 \mathrm{~h})$, 
according to the experimental protocols. Subsequently, $20 \mu \mathrm{l}$ MTT $(5 \mathrm{mg} / \mathrm{ml})$ was added to each well and incubated at $37^{\circ} \mathrm{C}$ for $4 \mathrm{~h}$. The medium was removed, and $150 \mu \mathrm{l}$ DMSO was added to each well. After shaking for $10 \mathrm{~min}$, the absorbance at $490 \mathrm{~nm}$ was measured in a microplate reader (Bio-Rad Laboratories, Inc.).

Hoechst staining. SH-SY5Y cells (Mock, WT or A53T, according to the aforementioned treatments) were plated in 6 -well plates at a density of $1 \times 10^{5}$ cells/well and treated with DMSO, or 10 or $20 \mu \mathrm{M}$ SAL for $24 \mathrm{~h}$. The cells were washed in PBS three times and incubated in $0.5 \mathrm{ml}$ Hoechst 33258 (Beyotime Institute of Biotechnology; cat. no.C-0003) solution $(5 \mu \mathrm{g} / \mathrm{ml})$ at $4^{\circ} \mathrm{C}$ overnight. Finally, fluorescence microscopy (magnification, x200) was performed to observe the nuclear changes in SH-SY5Y cells with the various treatments. Each group was analyzed in triplicate.

Western blotting. Treated cells were harvested and lysed in lysis buffer with complete protease inhibitors and phosphatase inhibitors on ice. Proteins were extracted on ice for $>1 \mathrm{~h}$ with occasional gentle vortexing, and debris and insoluble materials were pelleted by centrifugation at $14,000 \mathrm{x}$ g for $10 \mathrm{~min}$ at $4^{\circ} \mathrm{C}$. Pierce $^{\text {TM }}$ BCA Protein Assays (Thermo Fisher Scientific, Inc.; cat. no. 23225) were used to determine the concentration of protein, according to the manufacturer's protocol. A total of $20 \mu \mathrm{g}$ total proteins were loaded for SDS-PAGE (10-15\%), separated, and transferred onto a nitrocellulose membrane. The immunoblots were incubated in $3 \%$ bovine serum albumin (BSA), $10 \mathrm{mmol} / \mathrm{l}$ Tris- $\mathrm{HCl}$ ( $\mathrm{pH} 7.5), 1 \mathrm{mmol} / 1$ EDTA, and $0.1 \%$ Tween-20 at room temperature for $1 \mathrm{~h}$ before being probed with primary (overnight at $4^{\circ} \mathrm{C}$ ) and appropriate secondary antibodies $\left(1: 1,000\right.$, for $1 \mathrm{~h}$ at $\left.37^{\circ} \mathrm{C}\right)$. Primary antibody dilutions were as follows: $\alpha$-Syn, 1:6,000; pSer129- $\alpha$-syn, 1:5,000; PI3K, 1:1,000; p-PI3K, 1:1,000; mTOR, 1:2,000; p70S6K, 1:5,000; p-p70S6K, 1:1,000; Akt, 1:1,000; p-Akt, 1:2,000; LC3B, 1:2,000; and GAPDH, 1:2,000. Protein bands were visualized using enhanced chemiluminescence (cat. no. WBKLS0100; Merck KGaA), and protein quantification was performed using Image J software (version 1.52; National Institutes of Health).

Immunocytochemistry. SH-SY5Y cells treated with various solutions were grown on poly-L-lysine-coated slides and fixed with $4 \%$ paraformaldehyde for $15 \mathrm{~min}$ at room temperature, permeabilized with $0.1 \%$ Triton X-100 for $30 \mathrm{~min}$, and then blocked in $2 \%$ BSA in PBS for $1 \mathrm{~h}$ at room temperature. Cells were washed three times with PBS and incubated at $4^{\circ} \mathrm{C}$ overnight with primary antibodies against pSer129- $\alpha$-syn (1:500) or LC3B (1:500). The next day, the cells were washed with PBS and labeled with Alexa Fluor 555-conjugated donkey anti-rabbit $\mathrm{IgG}(\mathrm{H}+\mathrm{L})$ and Alexa Fluor 488-conjugated goat anti-rabbit $\operatorname{IgG}(\mathrm{H}+\mathrm{L})$ (both 1:200) for $2 \mathrm{~h}$ at room temperature. The nuclei were labeled with DAPI for $10 \mathrm{~min}$ at $4^{\circ} \mathrm{C}$. The final images were observed using a laser-scanning confocal microscope (magnification, $\mathrm{x} 400$ ).

Statistical analysis. All statistics were analyzed with SPSS software 14.0 (SPSS, Inc.). All experiments were performed three times, and the data are presented as the mean \pm SD.
One-way ANOVA with Tukey's post hoc test was used to assess multiple groups of data and the Student's t-test was used to compare two groups. $\mathrm{P}<0.05$ was considered to indicate a statistically significant difference.

\section{Results}

SAL protects $P D$ model neurons with $\alpha$-syn aggregation from apoptosis. SH-SY5Y cells were transfected with blank vector (mock), WT $\alpha$-syn plasmid, or the A53T mutation of $\alpha$-syn (A53T $\alpha$-syn) plasmid, giving a total of three experimental groups: Mock-SH, WT-SH, and Mut-SH, respectively. Firstly, it was indicated that both WT and A53T- $\alpha$-syn plasmid were successfully overexpressed in cells transfected with the overexpression plasmids by western blotting (Fig. 1A). Hence, W-SH and M-SH were established as PD model neurons with $\alpha$-syn aggregation. Neurons from each group were treated with three different SAL concentrations $(0,10$ and $20 \mu \mathrm{M}$ ), and examined for cell apoptosis at various time points using the MTT test and Hoechst staining. Among the three groups with no SAL treatment (Mock-SH-0, WT-SH-0 and Mut-SH-0), the cell proliferation indexes of WT-SH-0 and Mut-SH-0 were both lower than that of Mock-SH-0, especially at the $48 \mathrm{~h}$ time point. The result suggested that increased $\alpha$-syn expression in WT-SH and Mut-SH and potential subsequent formation of $\alpha$-syn aggregates affected cell proliferation in a time-dependent manner; thus, a cell model of PD was established (Fig. 1B). In the SAL-treated groups, the cell proliferation index was increased in both the WT-SH and Mut-SH groups in a dose-dependent manner (Fig. 1C). On the other hands, the results of the Hoechst staining indicated that SAL could protect SH-SY5Y with $\alpha$-syn aggregation (WT or A53T Mut) from apoptosis (Fig. 1D and E).

SAL inhibits $\alpha$-syn phosphorylation and restores autophagy in $P D$ model neurons. The phosphorylation of $\alpha$-syn (at Ser129) is considered a promoter of abnormal $\alpha$-syn aggregation. SH-SY5Y cells transfected with the three different plasmids (Mock-SH, W-SH and Mut-SH) were treated with three different SAL concentrations $(0,10$ and $20 \mu \mathrm{M})$, and cells cultured in serum-free medium were used as the positive control (20). The level of $\alpha$-syn phosphorylation was decreased by SAL in all three groups, and in a dose-dependent manner in both the WT-SH and Mut-SH groups (Fig. 2A and B).

LC3 is currently considered to be a marker of autophagy. LC3-I is cytosolic, and LC3-II is membrane bound, and this was the most fully characterized mammalian protein identified to be specifically and essentially associated with autophagosome membranes (21). Immunofluorescence results demonstrated that the expression of LC3-II in W-SH-0 and M-SH-0 was lower than that in $\mathrm{B}-\mathrm{SH}-0$, indicating that the autophagic function of both $\mathrm{W}-\mathrm{SH}$ and $\mathrm{M}-\mathrm{SH}$ was impaired. The levels of LC3-II in all three cell models (B-SH, W-SH and $\mathrm{M}-\mathrm{SH}$ ) were increased by SAL, and the results of the western blot experiments indicated that the ratio of LC3-II:LC3-I was increased by SAL treatment, also in a dose-dependent manner (Fig. 2C and D). These results implied that SAL could repair autophagic function in SH-SY5Y cells that have $\alpha$-syn aggregation. 
A
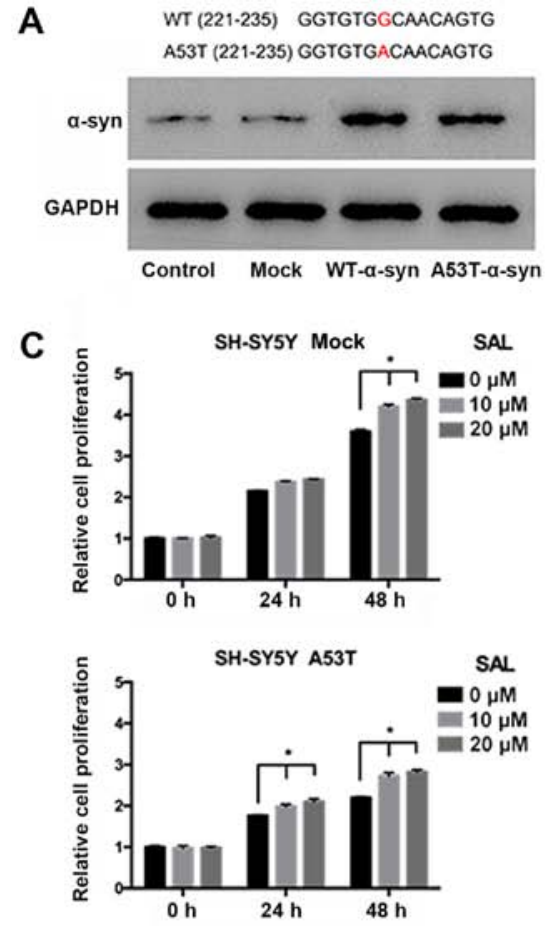

D
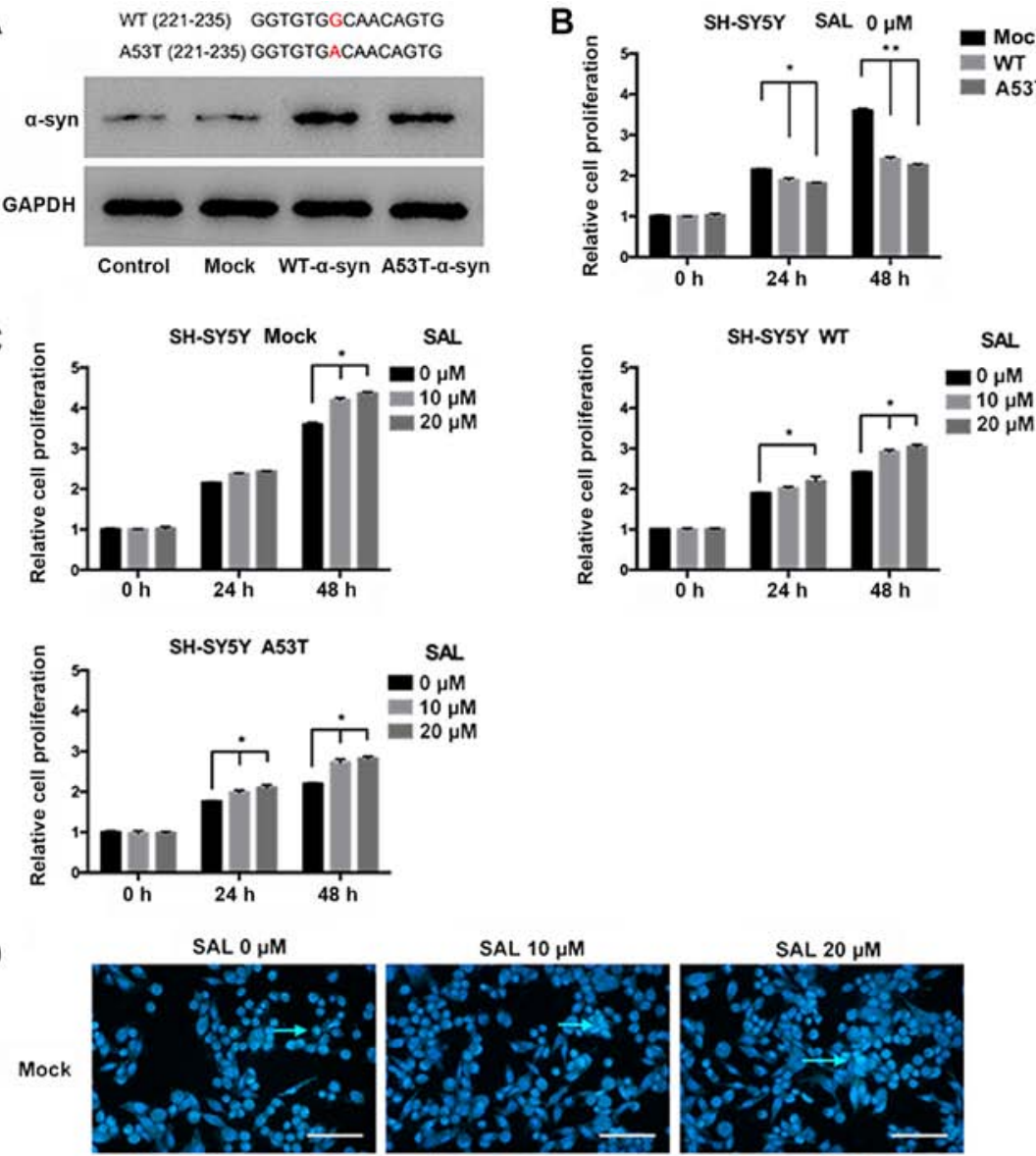

WT
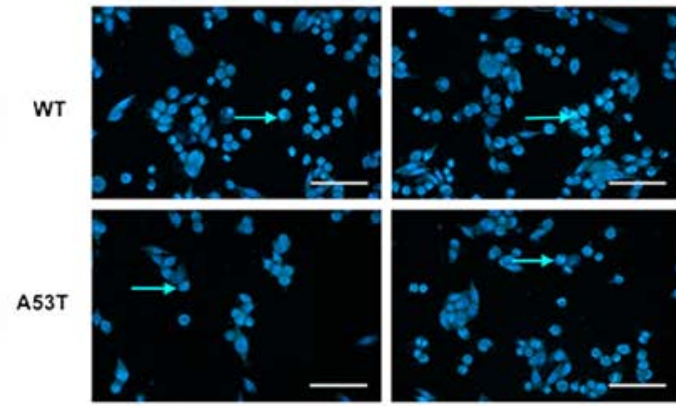

E

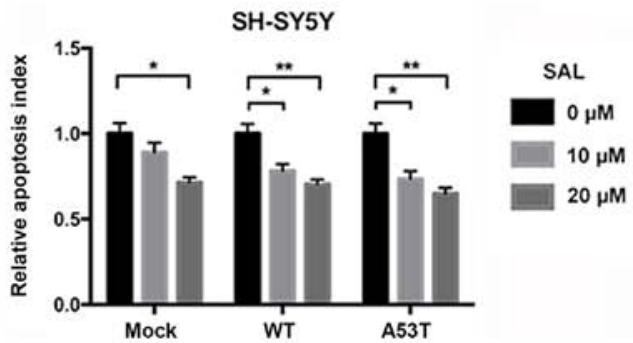

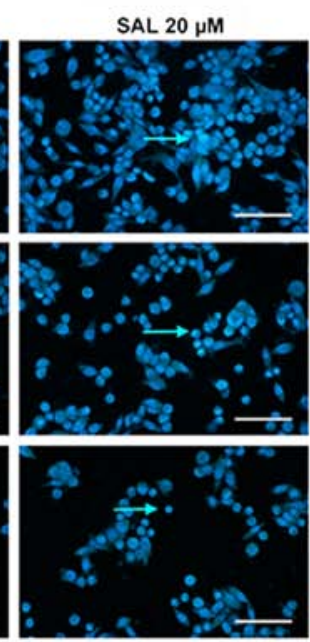

Figure 1. SAL protects Parkinson's disease model neurons with $\alpha$-syn aggregation in a dose-dependent manner. (A) SH-SY5Y cells transfected with WT- or A53T- $\alpha$-syn overexpression plasmids were assessed for overexpressed WT or A53T $\alpha$-syn by western blotting. The red letters above indicate the mutation site in A53T $\alpha$-syn. (B) Relative cell proliferation index comparison of the three neuron groups, mock, WT and A53T, without SAL treatment (0 $\mu \mathrm{M}$ SAL). The proliferation indexes of both the WT and A53T groups were decreased compared to that of the mock group at 24 and $48 \mathrm{~h}$. (C) Effects of SAL treatment on the viability of the three groups of SH-SY5Y cells. The neurons of each group were treated with various concentrations of SAL (0, 10 and $20 \mu \mathrm{M})$ for $24 \mathrm{~h}$ and 48 h. (D) Hoechst staining of each group of neurons with varying concentrations of SAL treatment. Apoptotic neurons, with compact and heavily stained nuclei, are indicated by the cyan arrows (scale bar, $100 \mu \mathrm{m}$ ). (E) The relative apoptosis indexes of SH-SY5Y cells were significantly lower in the SAL treatment $(10$ or $20 \mu \mathrm{M})$ subgroups than in the no SAL treatment $(0 \mu \mathrm{M})$ subgroup, in WT or A53T SH-SY5Y cells. One-way ANOVA was used to assess multiple groups of data. All data are expressed as the mean $\pm \mathrm{SD} .{ }^{*} \mathrm{P}<0.05 ;{ }^{* *} \mathrm{P}<0.01$. SAL, salidroside; A53T, A53T mutation; WT, wild-type; $\alpha$-syn, $\alpha$-synuclein.

Protective effect of SAL against $\alpha$-syn aggregation in PD model neurons is affected by Rap and 3-MA. The M-SH model was used in this experiment, and there were five treatment groups for this model: DMSO, $10 \mu \mathrm{M} \mathrm{SAL}, 10 \mu \mathrm{M} \mathrm{SAL}+5 \mu \mathrm{M}$ Rap (an mTOR inhibitor, used to induce mild autophagy in neurons), $10 \mu \mathrm{M} \mathrm{SAL}+1 \mathrm{mM}$ 3-MA (an autophagy inhibitor), 
A
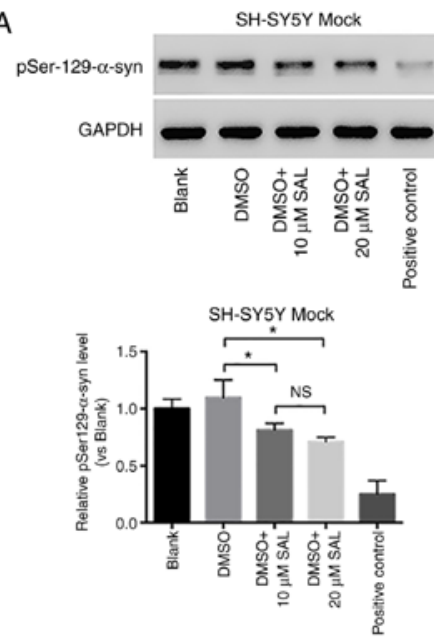

B

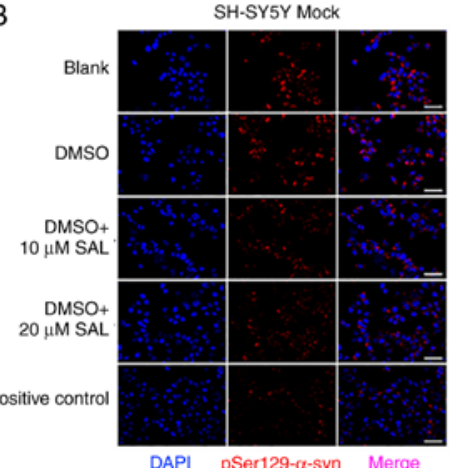

C
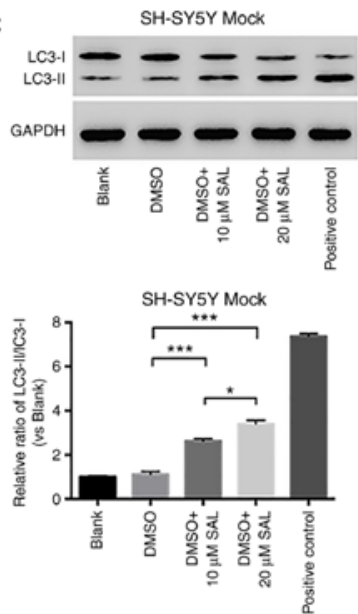

D

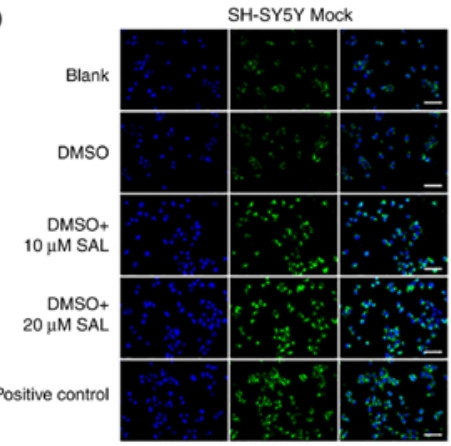

SH-SY5Y WT

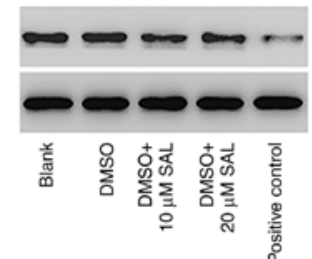

SH-SYSYWT

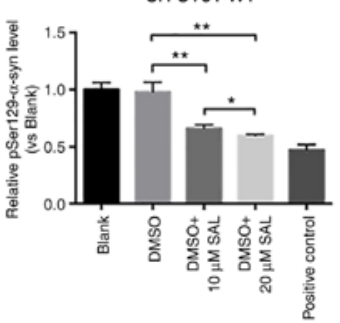

SH-SY5Y WT

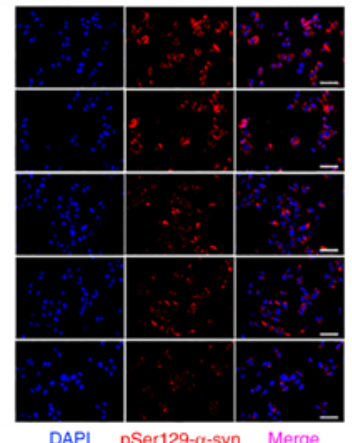

SH-SY5YWT
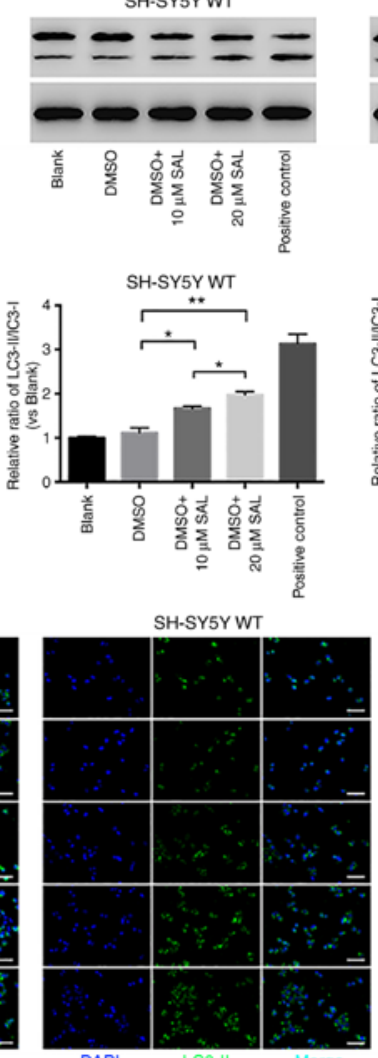

SH-SY5Y A53T

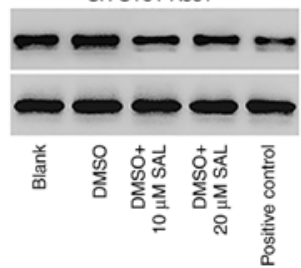

SH-SY5Y A53T

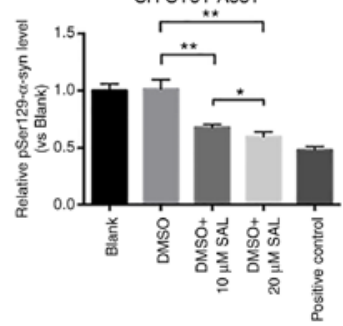

SH-SY5Y A53T

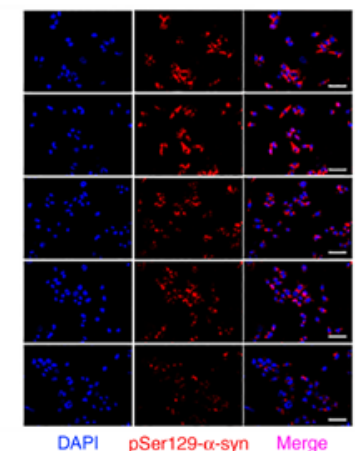

SH-SY5Y A53T
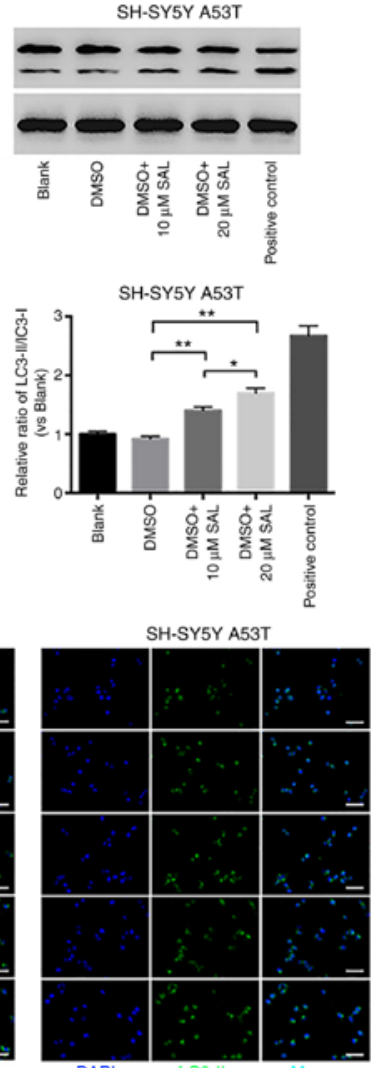

Figure 2. SAL decreased the expression of pSer129- $\alpha$-syn and restored autophagy in SH-SY5Y Parkinson's disease model neurons. (A) Western blot analysis of pSer129- $\alpha$-syn in each group of SH-SY5Y cells (mock, WT and A53T) with various treatments (Blank, DMSO, $10 \mu$ M SAL, $20 \mu \mathrm{M} \mathrm{SAL}$ and positive control). (B) Immunofluorescence staining of pSer129- $\alpha$-syn (red) in each group of SH-SY5Y cells (mock, WT and A53T) with various treatments at $24 \mathrm{~h}$ (scale bar, $50 \mu \mathrm{m}$ ). (C) Western blot analysis of LC3-II/LC3-I in each group of SH-SY5Y cells (mock, WT and A53T) with various treatments (blank, DMSO, $10 \mu \mathrm{M}$ SAL, $20 \mu \mathrm{M}$ SAL and positive control). (D) Immunofluorescence staining of LC3-II (green) in each group of SH-SY5Y cells (mock, WT, and A53T) with various treatments at $24 \mathrm{~h}$ (scale bar, $50 \mu \mathrm{m}$ ). ${ }^{*} \mathrm{P}<0.05 ;{ }^{* *} \mathrm{P}<0.01 ;{ }^{* * *} \mathrm{P}<0.001$. NS, not significant; SAL, salidroside; A53T, A53T mutation; WT, wild-type; $\alpha$-syn, $\alpha$-synuclein; DMSO, dimethyl sulfoxide; pSer129- $\alpha$-syn, phosphorylated $\alpha$-syn; LC3, microtubule-associated proteins 1A/1B light chain 3. 
and cells cultured in serum-free medium (as the positive control). The MTT results indicated that the relative cell proliferation value of the $10 \mu \mathrm{M} \mathrm{SAL}+5 \mu \mathrm{M}$ Rap group was higher than that of the $10 \mu \mathrm{M}$ SAL group, while the value of the $10 \mu \mathrm{M} \mathrm{SAL}+1 \mathrm{mM} 3$-MA group was much lower than that of the $10 \mu \mathrm{M}$ SAL group. These results indicated that the protective effect of SAL on the PD model neurons (Fig. 1) could be enhanced by Rap, but was inhibited by 3-MA, especially at the 48-h time point (Fig. 3A and B). In addition, Rap intensified the inhibitory effect of SAL on $\alpha$-syn phosphorylation, but 3-MA appeared to attenuate the effect of SAL on $\alpha$-syn phosphorylation (Fig. 3C and D), indicating that SAL may protect SH-SY5Y PD model neurons against $\alpha$-syn aggregation through autophagy via PI3K/mTOR signaling.

SAL preserves the autophagic function of M-SH cells via the inhibition of $m T O R / p 70 S 6 K$, independent of PI3K/Akt signaling. Additionally, in Mut-SH neurons, SAL $(10 \mu \mathrm{M})$ treatment decreased the expression of phosphorylated mTOR and p70S6K, but increased the ratio of LC3-II to LC3-I. The impact of SAL treatment was promoted by Rap $(5 \mu \mathrm{M})$ and reversed by 3-MA $(1 \mathrm{mM})$. Conversely, the levels of phosphorylated PI3K and Akt, two upstream proteins of PI3K/Akt/mTOR signaling, were both increased by SAL, and treatment with Rap further elevated the levels of both phosphorylated proteins, while 3-MA treatment reduced their levels (Fig. 4). These results indicated that SAL may preserve the autophagic function of SH-SY5Y cells with $\alpha$-syn aggregation by inhibiting mTOR/p70S6K, but that this effect is independent of PI3K/Akt signaling.

\section{Discussion}

Accumulation of misfolded $\alpha$-syn into aggregates is considered part of the pathogenesis of PD. During the pathogenic process, the misfolded $\alpha$-syn forms insoluble protein amyloid fibrils known as Lewy bodies, the pathological hallmark of this disease (22). Aside from point mutations (e.g. p.A53T, p.A30P, and p.E46K) and single nucleotide polymorphisms of $S N C A$ that alter the $\alpha$-syn protein structure, gene multiplications or normal aging can also lead to significantly increased cytoplasmic levels of soluble $\alpha$-syn, and are also associated with PD (23). This suggests that simply decreasing the cellular levels of $\alpha$-syn protein, which is the source of the misfolded $\alpha$-syn or $\alpha$-syn aggregates, is a possible therapeutic strategy against PD, especially in elderly patients with sporadic disease. A PD model was established by transfecting WT or p.A53T mutant (to increase the propensity for aggregate formation) (24) $\alpha$-syn-overexpressing plasmids into SH-SY5Y cells, which is a common cell model used in PD research.

It is known that the $\alpha$-syn protein undergoes extensive post-translational modifications, such as phosphorylation, nitration and dopamine modification, which all tend toward the oligomerization of $\alpha$-syn (25). Phosphorylation at Ser129 (pSer129) of $\alpha$-syn is the most prevalent modification in PD brains (26). More importantly, the phosphorylation of $\alpha$-syn at Ser1 29 can promote the accumulation of oligomeric $\alpha$-syn in SH-SY5Y cells (27), cause neuronal loss in transgenic mice overexpressing $\alpha$-syn (28), and affect $\alpha$-syn solubility and subcellular distribution (29). Therefore, phosphorylation at Ser129 is implicated in the PD process, and was used as a disease indicator in the present study.

Autophagy has been demonstrated to be cytoprotective during brain aging and neurodegeneration (30). In particular, $\alpha$-syn can be degraded either by autophagy or by proteasomes, but the degradation of toxic oligomeric $\alpha$-syn can only be initiated by the autophagy-lysosome pathway, rather than by proteasomes (31). Furthermore, mutant $\alpha$-syn actually inhibits chaperone-mediated autophagy (32), while WT $\alpha$-syn inhibits macroautophagy (33). It thus seems reasonable that breaking the interaction between $\alpha$-syn and the autophagy pathway may be an effective therapy for PD, although the mechanism is still not well understood.

SAL is the main bioactive component in Rhodiola rosea L., a botanical medicine that has historically been used widely in Asia, Europe and North America to prevent and treat a large variety of diseases (34). It has been reported that the pharmacological effects of SAL are effective against Alzheimer's disease, PD, stroke, depression, cancer, and diabetes, and provide organ protection and neurofunctional improvement. Although some studies have investigated the neuroprotective role of SAL, the exact mechanisms are not clear (35). The present study provides the first evidence, to the best of our knowledge, that SAL protects neurons in a PD model (SH-SY5Y with pathogenic $\alpha$-syn) from misfolded $\alpha$-syn aggregate toxicity, by stimulating autophagy and thereby reducing $\alpha$-syn aggregation. Furthermore, this study demonstrated that mTOR/p70S6K signaling mediated the effects of SAL on PD by inducing autophagy.

Previous studies have confirmed that SAL can efficiently protect PD model cells via various mechanisms. It has been demonstrated that SAL has protective effects on MPTP/MPP+ models of PD by reducing $\alpha$-syn aggregation through modulation of the ROS-NO-related mitochondrial pathway, both in vitro and in vivo (36). Moreover, SAL was also reported to prevent 1-methyl-4-phenylpyridinium (MPP+)-induced apoptosis in PC12 cells, partly through activation of the PI3K/Akt pathway (37). MPP+, the active metabolite of MPTP, acts as a selective toxin for DA neurons, finally leading to oxidative stress in the neurons via the ROS/NO-related mitochondrial pathway that promotes $\alpha$-syn aggregation. These factors therefore interact in the pathophysiology of PD $(38,39)$. In the present study, SH-SY5Y cells overexpressing WT/A53T- $\alpha$-syn were the PD cell model, and numerous misfolded $\alpha$-syn aggregates were the direct pathogenic factor. More importantly, it was verified that SAL could decrease the level of phosphorylated $\alpha$-syn, which is the source of $\alpha$-syn aggregation, and clear $\alpha$-syn aggregation by autophagy through mTOR/p70S6K activation, independently of PI3K/Akt. However, it remains possible that SAL may repair the abnormal ROS/NO mitochondrial pathway that was secondarily impaired by $\alpha$-syn aggregation in the present study. Additionally, the PI3K/Akt pathway is involved in survival and the inhibition of apoptosis in different cells via PI3K activity and the phosphorylation of Akt at serine residue 473 (Ser473), leading to the inhibition of apoptotic machinery molecules such as Bcl-2, BAD, Caspase 9 and Fas ligand (40). Therefore, the results from the present study and a previously published study (33) are not paradoxical; that is, SAL may rescue PD model cells not only via autophagy, induced by the 

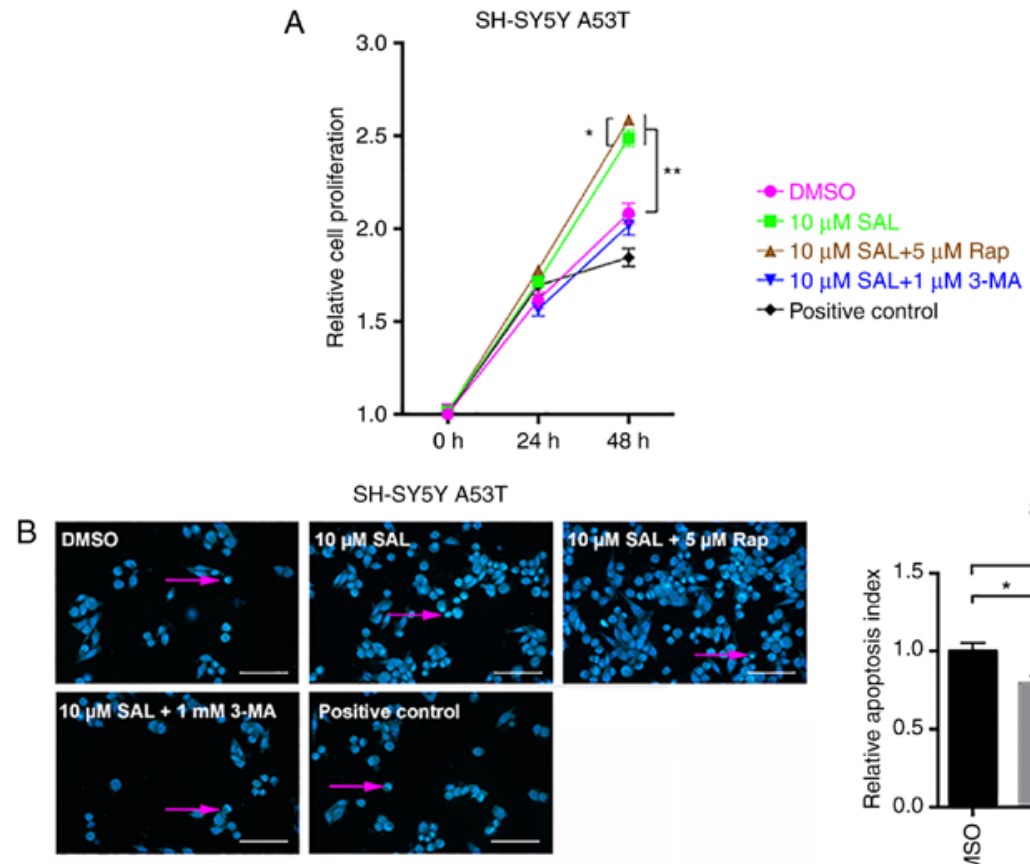

SH-SY5Y A53T
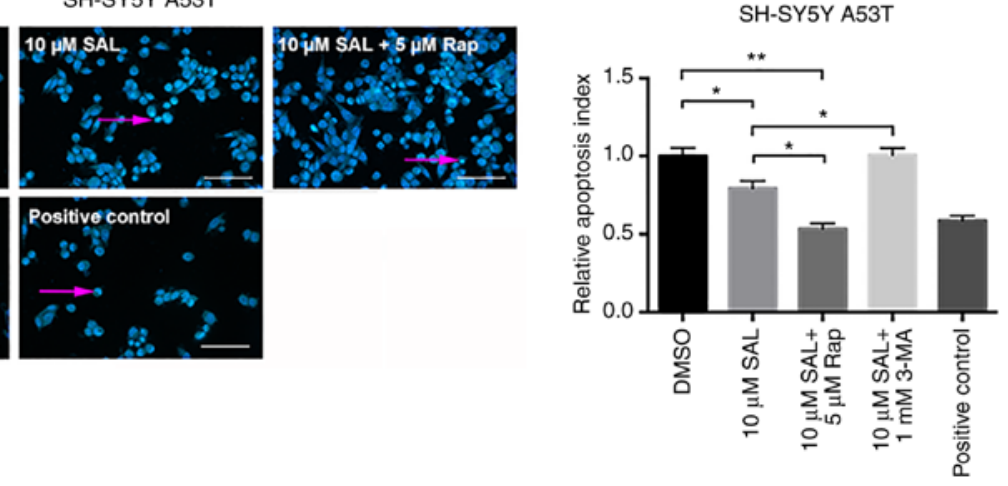

SH-SY5Y A53T
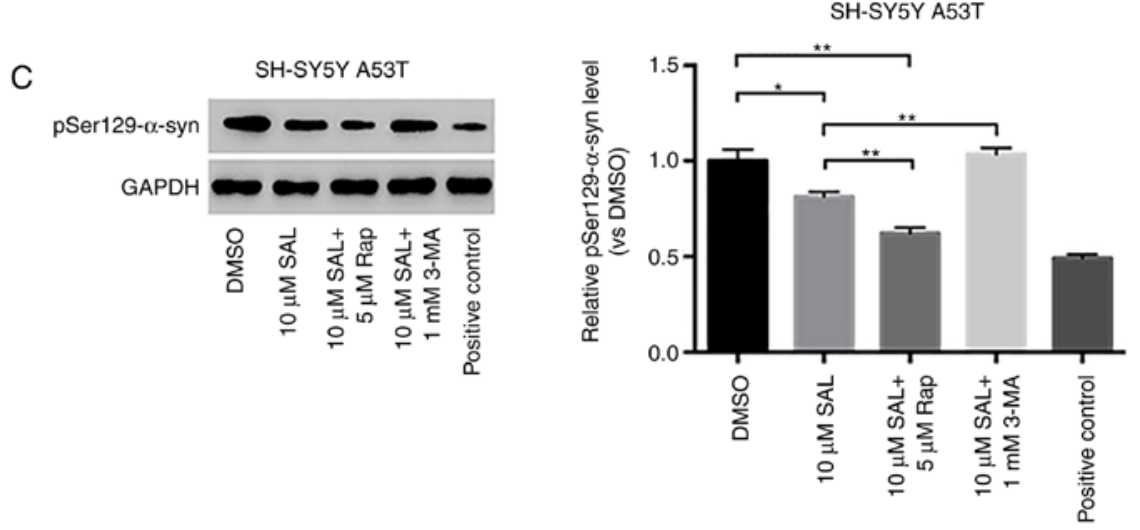

D

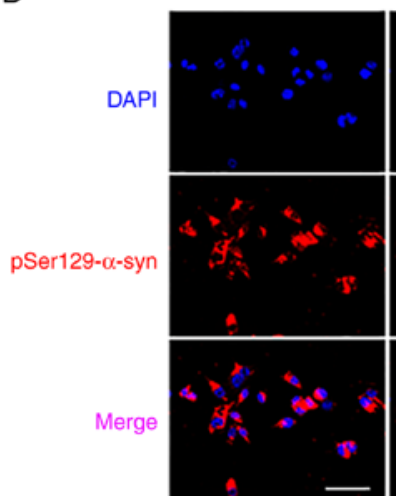

DMSO

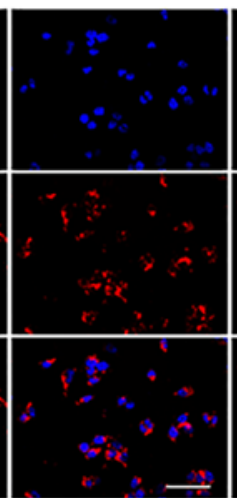

$10 \mu \mathrm{M} \mathrm{SAL}$

SH-SY5Y A53T

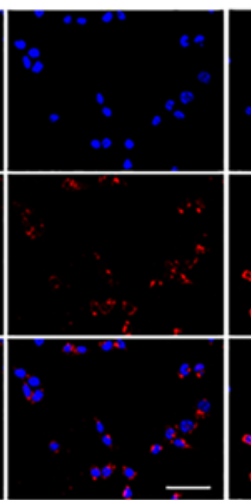

$10 \mu \mathrm{M} \mathrm{SAL}+$ $5 \mu \mathrm{M}$ Rap

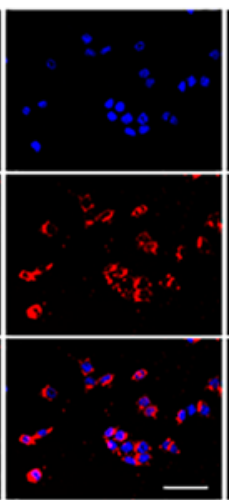

$10 \mu \mathrm{M} \mathrm{SAL}+$

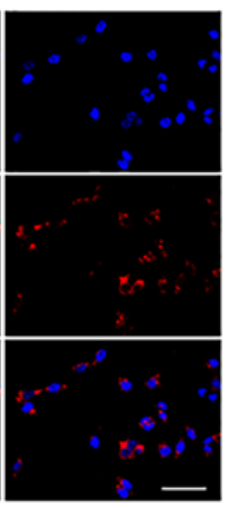

Positive control

Figure 3. Rapamycin and 3-methyladenine influenced the protective effect of SAL on SH-SY5Y Parkinson's disease model neurons with $\alpha$-syn aggregation (A) Relative cell proliferation index comparison of SH-SY5Y PD model neurons with various treatments (DMSO, $10 \mu \mathrm{M} \mathrm{SAL}, 10 \mu \mathrm{M}$ SAL $+5 \mu \mathrm{M}$ Rap, $10 \mu \mathrm{M}$ SAL $+1 \mathrm{mM}$ 3-MA and positive control) at different time points $(0,24$ and $48 \mathrm{~h}$ ). (B) Hoechst staining of A53T SH-SY5Y cells with various treatments (DMSO, $10 \mu \mathrm{M} \mathrm{SAL}, 10 \mu \mathrm{M} \mathrm{SAL}+5 \mu \mathrm{M} \mathrm{Rap}, 10 \mu \mathrm{M} \mathrm{SAL}+1 \mathrm{mM}$ 3-MA and positive control). Apoptotic neurons, with compact and heavily stained nuclei, are indicated by pink arrows (scale bar, $100 \mu \mathrm{m}$ ). (C) Western blot analyses of A53T SH-SY5Y cells with various treatments (DMSO, $10 \mu \mathrm{M}$ SAL, $10 \mu \mathrm{M} \mathrm{SAL}+5 \mu \mathrm{M}$ Rap, $10 \mu \mathrm{M} \mathrm{SAL}+1 \mathrm{mM} 3-\mathrm{MA}$ and positive control) at $24 \mathrm{~h}$ for the pSer129- $\alpha$-syn expression level. (D) Immunofluorescence staining of pSer129- $\alpha$-syn (red) of each group of A53T SH-SY5Y cells with various treatments at $24 \mathrm{~h}$ (scale bar, $50 \mu \mathrm{m}$ ). One-way ANOVA was used to assess multiple groups. All data are presented as the mean $\pm \mathrm{SD}$. " $\mathrm{P}<0.05 ;{ }^{* *} \mathrm{P}<0.01$. SAL, salidroside; A53T, A53T mutation; Rap, rapamycin; 3-MA, 3-methyladenine; $\alpha$-syn, $\alpha$-synuclein; DMSO, dimethyl sulfoxide; pSer129- $\alpha$-syn, phosphorylated $\alpha$-syn. 
A
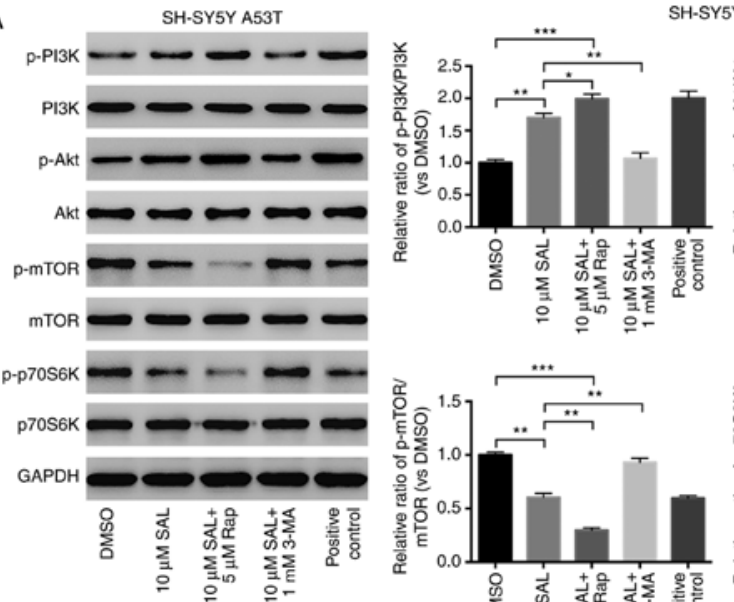

SH-SY5Y A53T
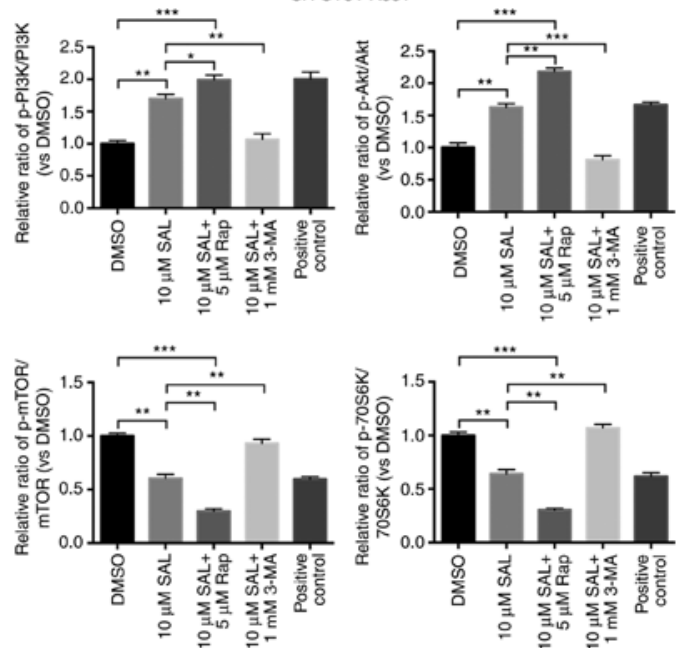

B

SH-SY5Y A53T
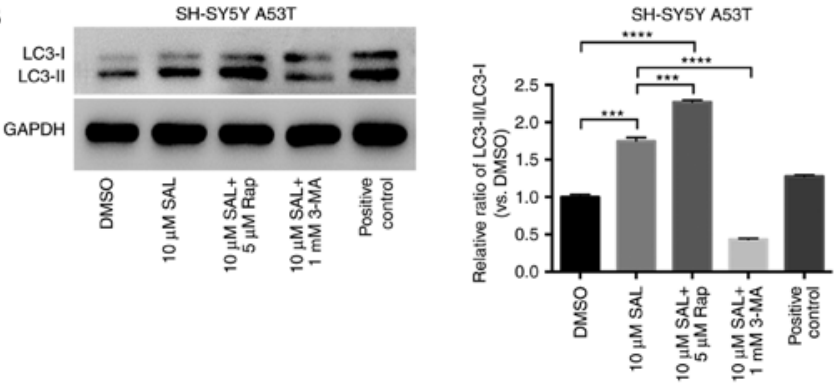

C

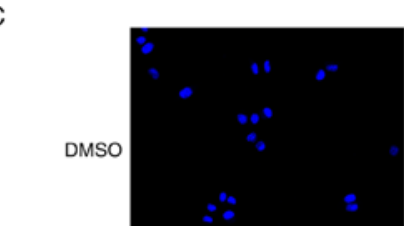

SH-SY5Y A53T
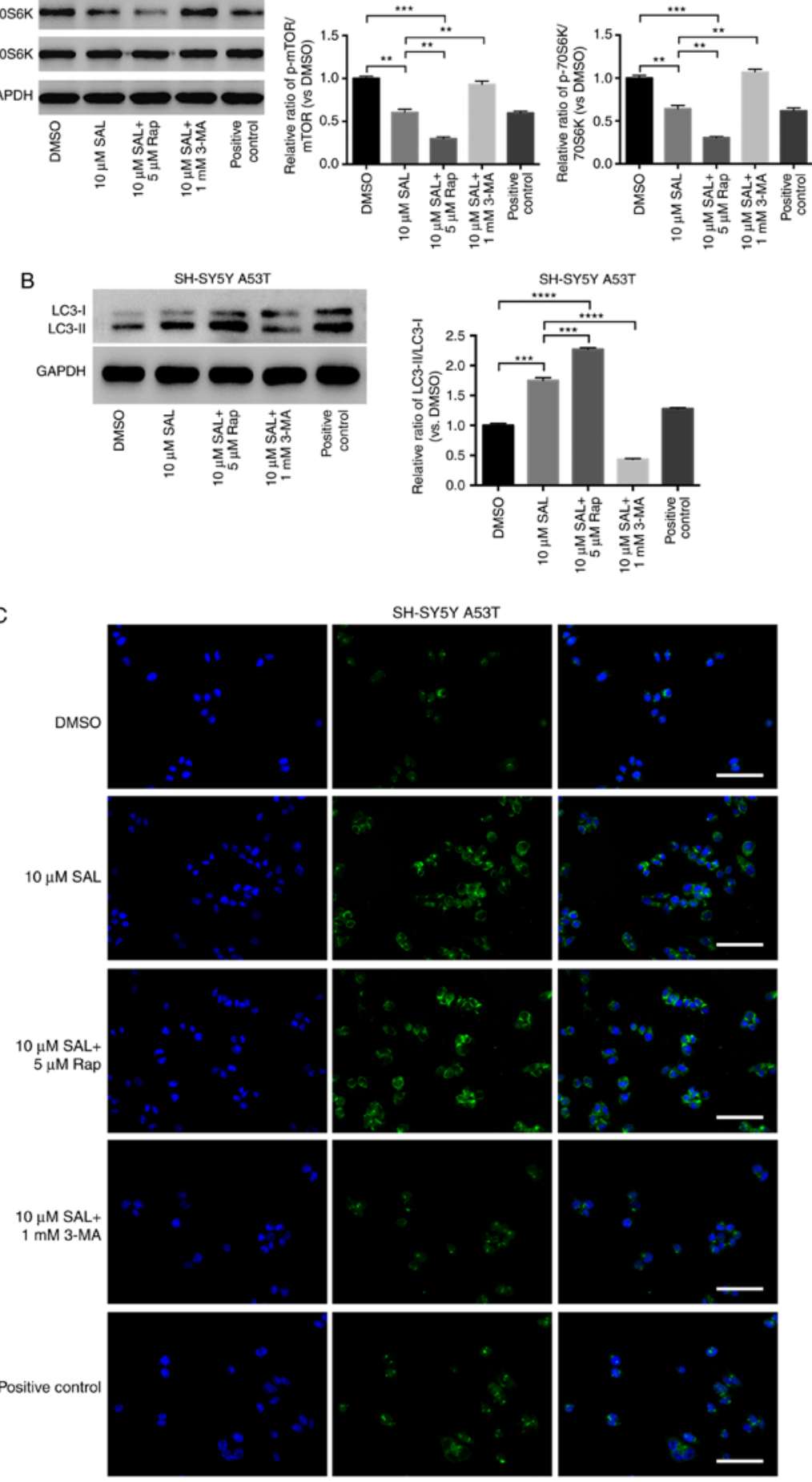

H.SY5Y A53T
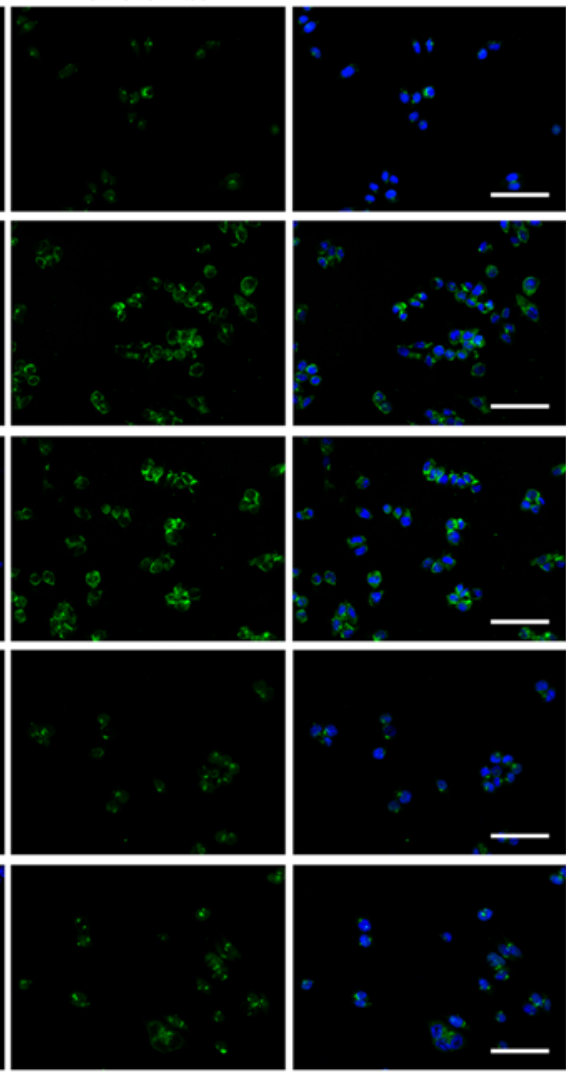

DAPI

LC3-11

Merge

Figure 4. SAL preserved the autophagy of A53T SH-SY5Y cells by inhibiting the phosphorylation of mTOR/p70S6K. Western blot analyses of A53T SH-SY5Y cells with various treatments (DMSO, $10 \mu \mathrm{M} \mathrm{SAL}, 10 \mu \mathrm{M} \mathrm{SAL}+5 \mu \mathrm{M}$ Rap, $10 \mu \mathrm{M} \mathrm{SAL}+1 \mathrm{mM} 3-\mathrm{MA}$, and the positive control) at $24 \mathrm{~h}$ for the expression level of (A) PI3K, Akt, mTOR, p70S6K, p-PI3K, p-Akt, p-mTOR, p-p70S6K, and (B) LC3-II/LC3-I. The ratios of LC3-II to LC3-I, as well as those of the phosphorylated proteins to the total relevant proteins in PI3K/Akt/mTOR/p70S6K signaling, were compared between the groups above. (C) Immunofluorescence staining of LC-II (green) in each group of A53T SH-SY5Y cells with various treatments at $24 \mathrm{~h}$ (scale bar, $50 \mu \mathrm{m}$ ). ${ }^{*} \mathrm{P}<0.05 ;{ }^{* * *} \mathrm{P}<0.01 ;{ }^{* * * *} \mathrm{P}<0.001 ;{ }^{* * * * *} \mathrm{P}<0.0001$ SAL, salidroside; A53T, A53T mutation; Rap, rapamycin; 3-MA, 3-methyladenine; DMSO, dimethyl sulfoxide; LC3, microtubule-associated proteins 1A/1B light chain 3; p, phosphorylated. 
inhibition of mTOR/p70S6K, but also via the promotion of survival through the direct activation of PI3K/Akt. Moreover, mTOR inhibition could stimulate the PI3K/Akt pathway via a negative feedback mechanism, so the anti-apoptosis effect of PI3K/Akt may be indirectly augmented. Lastly, it is not clear how mTOR may be inhibited by SAL, and this is a question for future research.

Besides autophagy, the ubiquitin-proteasome system (UPS) is the major degradation pathway in eukaryotic cells. The two systems share several common characteristics, and constrain each other (41). Previously, Li et al (42) used 6-hydroxydopamine and overexpression of WT-/A30P- $\alpha$-syn to establish a PD cell model in SH-SY5Y cells; it was found that SAL could promote $\alpha$-syn clearance and protect SH-SY5Y cells by restoring UPS activity, with the inhibition of autophagy. Therefore, although the present study demonstrated that SAL promoted autophagy via the inhibition of mTOR/p70S6K signaling to protect $\mathrm{SH}-\mathrm{SY} 5 \mathrm{Y}$ cells, it is also possible that SAL may impact signaling to maintain UPS function. In future research, it will be worthwhile to investigate the relationship between these two systems in PD pathogenesis, in order to develop new and improved pharmacological solutions for PD treatment.

In conclusion, the present study demonstrated for the first time, to the best of our knowledge, that SAL could inhibit the phosphorylation of $\alpha$-syn at Ser129, as well as the formation of WT/A53T- $\alpha$-syn aggregates in SH-SY5Y cells, by inducing autophagy via the inhibition of mTOR/p70S6K, independent of the PI3K/Akt pathway. These results suggest that SAL acts as a potential protective agent for DA neurons by restoring autophagic function and eliminating pathogenic $\alpha$-syn aggregation. However, it is necessary to further investigate the mechanisms underlying the protective effect of SAL on PD model neurons, to better understand the potential clinical implications for PD and other neurodegenerative diseases in the future.

\section{Acknowledgements}

The authors would like to thank Dr Bronwen Gardner for editing the English text of a draft of this manuscript.

\section{Funding}

This work was supported by the National Natural Science Foundation of China (grant nos. 81501113, 81502321 and 81771520), and funds from the Medical and Health Research Project of Zhejiang Province (grant nos. 2015KYA001, 2017KY188, 2014KYA089 and 2014KYA093).

\section{Availability of data and materials}

All data generated or analyzed during this study are included in this published article.

\section{Authors' contributions}

SC, JY and GM designed the study. SC, FC and JW performed the major experiments. SC, FC, GM, JY, ZY, GW and CG analyzed the data and discussed the results. SC and FC wrote the manuscript. SC, FC and CG revised the manuscript and figures. All authors approved the final version of the manuscript.

\section{Ethics approval and consent to participate}

Not applicable.

\section{Patient consent for publication}

Not applicable.

\section{Competing interests}

The authors declare that they have no competing interests.

\section{References}

1. Jenner P, Morris HR, Robbins TW, Goedert M, Hardy J, Ben-Shlomo Y, Bolam P, Burn D, Hindle JV and Brooks D: Parkinson's disease-the debate on the clinical phenomenology, aetiology, pathology and pathogenesis. J Parkinsons Dis 3: 1-11, 2013.

2. Spillantini MG, Schmidt ML, Lee VM, Trojanowski JQ, Jakes R and Goedert M: Alpha-synuclein in Lewy bodies. Nature 388: 839-840, 1997.

3. Jakes R, Spillantini MG and Goedert M: Identification of two distinct synucleins from human brain. FEBS Lett 345: 27-32, 1994.

4. Alves da Costa C, Dunys J, Brau F, Wilk S, Cappai R and Checler F: 6-Hydroxydopamine but not 1-methyl-4-phenylpyridinium abolishes alpha-synuclein anti-apoptotic phenotype by inhibiting its proteasomal degradation and by promoting its aggregation. J Biol Chem 281: 9824-9831, 2006.

5. Del Tredici K and Braak H: Review: Sporadic Parkinson's disease: Development and distribution of alpha-synuclein pathology. Neuropathol Appl Neurobiol 42: 33-50, 2016.

6. Volpicelli-Daley LA, Luk KC, Patel TP, Tanik SA, Riddle DM, Stieber A, Meaney DF, Trojanowski JQ and Lee VM: Exogenous $\alpha$-synuclein fibrils induce Lewy body pathology leading to synaptic dysfunction and neuron death. Neuron 72: 57-71, 2011.

7. Desplats P, Lee HJ, Bae EJ, Patrick C, Rockenstein E, Crews L, Spencer B, Masliah E and Lee SJ: Inclusion formation and neuronal cell death through neuron-to-neuron transmission of alpha-synuclein. Proc Natl Acad Sci USA 106: 13010-13015, 2009.

8. Hansen C, Angot E, Bergstrom AL, Steiner JA, Pieri L, Paul G, Outeiro TF, Melki R, Kallunki P, Fog K, et al: $\alpha$-Synuclein propagates from mouse brain to grafted dopaminergic neurons and seeds aggregation in cultured human cells. J Clin Invest 121: 715-725, 2011.

9. Luk KC, Kehm V, Carroll J, Zhang B, O'Brien P, Trojanowski JQ and Lee VM: Pathological alpha-synuclein transmission initiates Parkinson-like neurodegeneration in nontransgenic mice. Science 338: 949-953, 2012.

10. Mougenot AL, Nicot S, Bencsik A, Morignat E, Verchère J, Lakhdar L, Legastelois S and Baron T: Prion-like acceleration of a synucleinopathy in a transgenic mouse model. Neurobiol Aging 33: 2225-2228, 2012.

11. Tyedmers J, Mogk A and Bukau B: Cellular strategies for controlling protein aggregation. Nat Rev Mol Cell Biol 11: 777-788, 2010.

12. Danzer KM, Kranich LR, Ruf WP, Cagsal-Getkin O, Winslow AR, Zhu L, Vanderburg CR and McLean PJ: Exosomal cell-to-cell transmission of alpha synuclein oligomers. Mol Neurodegener 7: 42, 2012.

13. Tanik SA, Schultheiss CE, Volpicelli-Daley LA, Brunden KR and Lee VM: Lewy body-like alpha-synuclein aggregates resist degradation and impair macroautophagy. J Biol Chem 288: 15194-15210, 2013

14. Grech-Baran M, Syklowska-Baranek K and Pietrosiuk A: Biotechnological approaches to enhance salidroside, rosin and its derivatives production in selected Rhodiola spp. in vitro cultures. Phytochem Rev 14: 657-674, 2015.

15. Mao GX, Wang Y, Qiu Q, Deng HB, Yuan LG, Li RG, Song DQ, Li YY, Li DD and Wang Z: Salidroside protects human fibroblast cells from premature senescence induced by $\mathrm{H}(2) \mathrm{O}(2)$ partly through modulating oxidative status. Mech Ageing Dev 131: 723-731, 2010. 
16. Li X, Ye X, Li X, Sun X, Liang Q, Tao L, Kang X and Chen J: Salidroside protects against MPP(+)-induced apoptosis in PC12 cells by inhibiting the NO pathway. Brain Res 1382: 9-18, 2011.

17. Zhang L, Yu H, Zhao X, Lin X, Tan C, Cao G and Wang Z: Neuroprotective effects of salidroside against beta-amyloid-induced oxidative stress in SH-SY5Y human neuroblastoma cells. Neurochem Int 57: 547-555, 2010.

18. Zhu Y, Shi YP, Wu D, Ji YJ, Wang X, Chen HL, Wu SS, Huang DJ and Jiang W: Salidroside protects against hydrogen peroxide-induced injury in cardiac $\mathrm{H} 9 \mathrm{c} 2$ cells via PI3K-Akt dependent pathway. DNA Cell Biol 30: 809-819, 2011.

19. Chojnacki S, Cowley A, Lee J, Foix A and Lopez R: Programmatic access to bioinformatics tools from EMBL-EBI update: 2017. Nucleic Acids Res 45: W550-W553, 2017.

20. Mohan N, Banik NL and Ray SK: Combination of $\mathrm{N}$-(4-hydroxyphenyl) retinamide and apigenin suppressed starvation-induced autophagy and promoted apoptosis in malignant neuroblastoma cells. Neurosci Lett 502: 24-29, 2011.

21. Schaaf MB, Keulers TG, Vooijs MA and Rouschop KM: LC3/GABARAP family proteins: Autophagy-(un)related functions. FASEB J 30: 3961-3978, 2016.

22. Lashuel HA, Overk CR, Oueslati A and Masliah E: The many faces of alpha-synuclein: From structure and toxicity to therapeutic target. Nat Rev Neurosci 14: 38-48, 2013.

23. Chu Y and Kordower JH: Age-associated increases of alpha-synuclein in monkeys and humans are associated with nigrostriatal dopamine depletion: Is this the target for Parkinson's disease? Neurobiol Dis 25: 134-149, 2007.

24. Lee VM, Giasson BI and Trojanowski JQ: More than just two peas in a pod: Common amyloidogenic properties of tau and alpha-synuclein in neurodegenerative diseases. Trends Neurosci 27: 129-134, 2004.

25. Barrett PJ and Timothy Greenamyre J: Post-translational modification of alpha-synuclein in Parkinson's disease. Brain Res 1628 247-253, 2015.

26. Fujiwara H, Hasegawa M, Dohmae N, Kawashima A, Masliah E, Goldberg MS, Shen J, Takio K and Iwatsubo T: Alpha-Synuclein is phosphorylated in synucleinopathy lesions. Nat Cell Biol 4 160-164, 2002

27. Smith WW, Margolis RL, Li X, Troncoso JC, Lee MK, Dawson VL, Dawson TM, Iwatsubo T and Ross CA: Alphasynuclein phosphorylation enhances eosinophilic cytoplasmic inclusion formation in SH-SY5Y cells. J Neurosci 25: 5544-5552, 2005.

28. Schell H, Hasegawa T, Neumann M and Kahle PJ: Nuclear and neuritic distribution of serine-129 phosphorylated alphasynuclein in transgenic mice. Neuroscience 160: 796-804, 2009.

29. Zhou J, Broe M, Huang Y, Anderson JP, Gai WP, Milward EA, Porritt M, Howells D, Hughes AJ, Wang X and Halliday GM: Changes in the solubility and phosphorylation of $\alpha$-synuclein over the course of Parkinson's disease. Acta Neuropathol 121: 695-704, 2011.
30. Rubinsztein DC, Gestwicki JE, Murphy LO and Klionsky DJ: Potential therapeutic applications of autophagy. Nat Rev Drug Discov 6: 304-312, 2007.

31. Bennett MC, Bishop JF, Leng Y, Chock PB, Chase TN and Mouradian MM: Degradation of alpha-synuclein by proteasome. J Biol Chem 274: 33855-33858, 1999.

32. Cuervo AM, Stefanis L, Fredenburg R, Lansbury PT and Sulzer D: Impaired degradation of mutant alpha-synuclein by chaperone-mediated autophagy. Science 305: 1292-1295, 2004.

33. Winslow AR, Chen CW, Corrochano S, Acevedo-Arozena A, Gordon DE, Peden AA, Lichtenberg M, Menzies FM, Ravikumar B, Imarisio S, et al: $\alpha$-Synuclein impairs macroautophagy: Implications for Parkinson's disease. J Cell Biol 190: 1023-1037, 2010

34. Panossian A, Wikman G and Sarris J: Rosenroot (Rhodiola rosea): Traditional use, chemical composition, pharmacology and clinical efficacy. Phytomedicine 17: 481-493, 2010.

35. Zhong Z, Han J, Zhang J, Xiao Q, Hu J and Chen L: Pharmacological activities, mechanisms of action, and safety of salidroside in the central nervous system. Drug Des Devel Ther 12: 1479-1489, 2018.

36. Wang S, He H, Chen L, Zhang W, Zhang X and Chen J: Protective effects of salidroside in the MPTP/MPP(+)-induced model of Parkinson's disease through ROS-NO-related mitochondrion pathway. Mol Neurobiol 51: 718-728, 2015.

37. Zhang L, Ding W, Sun H, Zhou Q, Huang J, Li X, Xie Y and Chen J: Salidroside protects PC12 cells from $\mathrm{MPP}^{+}$-induced apoptosis via activation of the PI3K/Akt pathway. Food Chem Toxicol 50: 2591-2597, 2012.

38. Parihar MS, Parihar A, Fujita M, Hashimoto M and Ghafourifar P: Alpha-synuclein overexpression and aggregation exacerbates impairment of mitochondrial functions by augmenting oxidative stress in human neuroblastoma cells. Int J Biochem Cell Biol 41 : 2015-2024, 2009

39. Tsang $\mathrm{AH}$ and Chung KK: Oxidative and nitrosative stress in parkinson's disease. Biochim Biophys Acta 1792: 643-650, 2009.

40. Heras-Sandoval D, Perez-Rojas JM, Hernandez-Damian J and Pedraza-Chaverri J: The role of PI3K/AKT/mTOR pathway in the modulation of autophagy and the clearance of protein aggregates in neurodegeneration. Cell Signal 26: 2694-2701, 2014.

41. Kocaturk NM and Gozuacik D: Crosstalk between mammalian autophagy and the ubiquitin-proteasome system. Front Cell Dev Biol 6: 128, 2018.

42. Li T, Feng Y, Yang R, Wu L, Li R, Huang L, Yang Q and Chen J: Salidroside promotes the pathological alpha-synuclein clearance through ubiquitin-proteasome system in SH-SY5Y Cells. Front Pharmacol 9: 377, 2018

This work is licensed under a Creative Commons Attribution-NonCommercial-NoDerivatives 4.0 International (CC BY-NC-ND 4.0) License. 